\title{
Analysis of cupressuflavone and amentoflavone from Cupressus sempervirens $L$. and its tissue cultured callus using HPLC-dad method
}

\begin{abstract}
An HPLC-DAD method has been optimized and validated to obtain qualitative and quantitative profiles of cupressuflavone, and amentoflavone from Cupressus sempervirens $L$. compared to the content of micropropagated plants. The plants analyzed were collected from two geographical sources in Egypt; Cupressus from the north coast and Cupressus from Future University (Cairo, Egypt). Isocratic reversed phase HPLC separation was achieved using a $\mathrm{C}_{18}$ column $(150 \mathrm{~mm} \times 4.6 \mathrm{~mm} \mathrm{I.D.}, 5 \mu \mathrm{m})$. Good resolution between cupressuflavone and amentoflavone was achieved using a mixture of water: acetonitrile: formic acid (60: $40: 0.1 \%, \mathrm{v} / \mathrm{v})$ as a mobile phase at a flow rate of $1 \mathrm{mLmin}^{-1}$. Quantitation was achieved with photodiode array detector at the wavelength of maximum absorbance $(330 \mathrm{~nm})$ based on peak area. The method was effective in the determination of the analyses of interest without any interference of other compounds or the matrix. The method was linear over a concentration range of 0.5 $40 \mu \mathrm{gml}^{-1}\left(\mathrm{r}^{2}>0.999\right)$ for biflavonoids. The limits of detection were 0.15 and $0.14 \mu \mathrm{gml}-$ 1 and the limits of quantitation were 0.47 and $0.43 \mu \mathrm{gml}^{-1}$ for cupressuflavone and amentoflavone, respectively. Intraday and Interday precision (RSD\%) was less than $\pm 3 \%$ and intraday and Interday accuracy (RE\%) of the method was found to be less than $\pm 15 \%$ at all concentrations tested. The procedure was relatively simple, precise, rapid, reproducible, and could be routinely used for analysis of the cupressuflavone and amentoflavone flavonoids.
\end{abstract}

Keywords: Cupressus sempervirens, hplc-dad, cupressuflavone, amentoflavone, callus
Volume 5 Issue 5 - 2017

\author{
Elsayed A Ibrahim, ${ }^{1,3}$ SamarY Desoukey, ${ }^{2}$ \\ Ghada M Hadad, ${ }^{3}$ Randa A Abdel Salam, ${ }^{3}$ \\ Amany K Ibrahim, ${ }^{4}$ Safwat A Ahmed, ${ }^{4}$ \\ Mohamed M Radwan, ${ }^{1,5}$ Amira SWanas, ${ }^{2}$ \\ Mahmoud A ElSohly $1,4,5,6$ \\ 'National Center for Natural Products Research, University of \\ Mississippi, USA \\ ${ }^{2}$ Department of Pharmacognosy, Minia University, Egypt \\ ${ }^{3}$ Department of Pharmaceutical Analytical Chemistry, Suez \\ Canal University, Egypt \\ ${ }^{4}$ Department of Pharmacognosy, Suez Canal University, Egypt \\ ${ }^{5}$ Department of Pharmacognosy, Alexandria University, Egypt \\ ${ }^{6}$ Department of Pharmaceutics, The University of Mississippi, \\ USA
}

Correspondence: Mahmoud A ElSohly, National Center for Natural Products Research, School of Pharmacy, University of Mississippi, MS 38677, USA, Tel + |6629155928, Emailmradwan@olemiss.edu

Received: August 18, 2017 | Published:September 27, 2017
Abbreviations: HPLC, high pressure liquid chromatography; $\mathrm{DAD}$, diode array detector; RSD, relative standard deviation; RE, relative error; $\mathrm{CPF}$, cupressuflavone; $\mathrm{AMF}$, amentoflavone; $\mathrm{CNC}$, cupressus from north coast, Egypt; CFU, cupressus from future university, Egypt; MS, murashige and skoog medium; PGRS, plant growth regulators; NAA, $\beta$-naphthalene acetic acid; BA, 6-benzyladenine; $\mathrm{GA}_{3}$, gibberellic acid; PAL, phenylalanine; K', retention factor; Rs, resolution; $\alpha$, selectivity; $\mathrm{r}^{2}$, correlation coefficient; LOD, limit of detection; LOQ, limit of quantitation; SD, standard deviation

\section{Introduction}

Plants belonging to the genus Cupressus are found in many regions of the world especially in the northern hemisphere. In Egypt Cupressus sempervirens $L$., is a perennial conifer with tiny, scaly leaves. The aerial parts of the plant have been widely used in traditional folk medicine for many years. ${ }^{1}$ Vapors of the plant are used in the treatment of whooping cough and the aqueous extracts are used as antiseptic and dressings for the treatment of circulatory diseases such as hemorrhoids. ${ }^{2}$ In 1929 gingetin was the first isolated biflavonoid from plants. ${ }^{3}$ Nowadays more than one hundred biflavonoids are well recognized from different sources. ${ }^{4}$ Hegnauer reported that the main natural compounds of the Cupressus genus are the biflavonoids. The presence of amentoflavone (AMF) and cupressuflavone (CPF) was firstly reported by Gadek and Quinn in the leaves of $C$ sempervirens L., C. lusitanica L., and C. glabra L. and considered the most common biflavonoids found in the leaves and aerial parts of Cupressus. ${ }^{6}$ It was interesting that biflavonoids were reported as the major chemotaxonomic chemical compounds in Cupressus genus. ${ }^{7}$ The chemical structures of the main biflavonoids present in cypress species are presented in Figure 1. Various biological activities have been attributed to this natural bioflavonoid such as antidiabetic, antiinflammatory, antimicrobial, antioxidant, hypoglycemic, anticancer, peripheral vasodilatation and lipid peroxidation inhibitors. ${ }^{8-10}$ They also have antiviral effects on some viruses including HIV, hepatitis $\mathrm{B}, \mathrm{HSV}, \mathrm{HCMV}$, adenovirus and varicella-zoster virus and some antifungal activities. ${ }^{11,12}$ In vivo experiments presented biflavonoids as hepatoprotective, increased RNA synthesis in hepatocytes inhibited expression of EBV gene in addition to anti-spasmogenic activities and anti-bradykinin. ${ }^{13-16}$ Recently, it was shown that biflavonoids are effective in the management of tuberculosis and postmenopausal breast cancer. ${ }^{4-17}$ Two TLC chromatographic methods had been used to separate and determine biflavonoids and flavonoids from $C$. sempervirens $L .{ }^{18}$ Although many biflavonoids have been reported in the literature, complete identification and quantitation were unsatisfying. ${ }^{6-19}$ Romani et al. ${ }^{7}$ reported the first determination and quantification of the main individual polyphenols; flavonoid glycosides and biflavonoids in the leaf tissues from different Cupressus species using HPLC-DAD, HPLC-MS, and HPTLC. But these methods are very time consuming as the retention time of $\mathrm{CPF}$ and $\mathrm{AMF}$ was high and subsequently the consumption of large quantities of solvents. Thus, this study represents development and validation of new and time-saving reversed phase HPLC-DAD method and its sequential application for analysis of $\mathrm{CPF}$ and $\mathrm{AMF}$ from C. sempervirens micropropagated by tissue culture technique in addition to the native 
plants from two geographical sources, thus presenting a new study of the effect of growth hormones and media compositions on the selection of the best media to optimize the production of these two bioactive compounds.<smiles>O=c1cc(-c2ccc(O)cc2)oc2c(-c3c(O)cc(O)c4c(=O)c(-c5ccc(O)cc5)coc34)c(O)cc(O)c12</smiles>

Cupressuflavone (a)

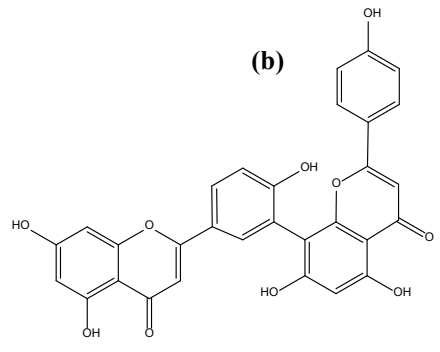

Amentoflavone

Figure I Chemical structures of A, Cupressuflavone (CPF); B,Amentoflavone (AMF).

\section{Materials and methods}

\section{Chemicals, reagents and plant}

All reagents and solvents were of analytical and HPLC grade. Acetonitrile and methanol HPLC grade were purchased from (Fisher Scientific, New Jersey, USA) in addition to DMSO and formic acid laboratory grade were purchased from (Fisher Scientific, New Jersey, USA). CPF and AMF standards were purchased from (PhytoLab, Dutendorfer, Germany) (Purity $>98.0 \%$, w/w by HPLC). For sample filtration, $0.45 \mathrm{pm}$ Millex-HV Millipore filters were used. Aerial parts of C. sempervirens were obtained from two different geographical sources: the first location is the Alameen, North coast Egypt (CNC) and the other location is the gardens of Future University, Cairo, Egypt (CFU). Murashige and Skoog medium (MS) ${ }^{20}$ supplemented with plant growth regulators (PGRS); $\beta$-Naphthalene acetic acid (NAA) and 6-Benzyladenine (BA) were purchased from (Sigma Cell Culture, min. 90\%, St. Louis, USA). Phytagel was from (Duchefa, Haarlem, Netherlands). Gibberellic acid (GA3) Phenylalanine (PAL) was purchased from Sigma-Aldrich.

\section{Instrumentation}

In the present method, the HPLC system used was Waters Alliance 2695e with binary HPLC pump equipped with Waters 2996 PDA detector. The acquisition and treatment of data were done by Empower 2 software. The analysis was carried out using a $\mathrm{C}_{18}$ column $(150 \mathrm{~mm} \times$ 4.6mm I.D., $5 \mu \mathrm{m}$, Luna, Toronto, Canada).

\section{Standard solutions and calibration}

Stock standard solutions of CPF and AMF were prepared by dissolving $5 \mathrm{mg}$ of each compound in $5 \mathrm{~mL}$ solution mixture of acetonitrile: DMSO $(1: 1, \mathrm{v} / \mathrm{v})$. The standard solutions were stored at $4^{\circ} \mathrm{C}$. Working standard solutions were prepared daily by diluting the standard stock solutions with acetonitrile. Nine points were used to construct calibration curve $\left(0.5,1,2,5,10,20,25,30,40 \mu \mathrm{gml}^{-1}\right)$ for both $\mathrm{CPF}$ and $\mathrm{AMF}$.

\section{HPLC analysis}

HPLC method was developed and validated using a $\mathrm{C}_{18}$ column $((150 \mathrm{~mm} \times 4.6 \mathrm{~mm}$ I.D., $5 \mu \mathrm{m})$. The column temperature was maintained at $25 \pm 1{ }^{\circ} \mathrm{C}$. Good resolution between CPF and AMF was accomplished using a mixture of water: acetonitrile: formic acid (60: 40: 0.1\%, v/v) as a mobile phase at flow rate $1 \mathrm{~mL} / \mathrm{min}$. The samples were filtered through $0.45 \mu \mathrm{m}$ pore size disposable filters prior to injection. The injection volume was $5 \mu \mathrm{L}$. The validation procedures and quantitation of the analyses were achieved with UV detection at $330 \mathrm{~nm}$ based on peak area.

\section{Culture media and conditions}

For production of the tissue cultured callus; autoclave used was (Harvey Sterilemax autoclave, Thermo Scientific, USA) and fluorescent tubes were from (F140t9d/38, Toshiba). Leaves explants were cut into pieces $(0.5-1.0 \mathrm{~cm})$ and then cultured aseptically on solid full strength basal (MS) medium ${ }^{20}$ with the addition of plant growth regulators (PGRs); $0.5 \mathrm{mg} \mathrm{L}^{-1} \mathrm{BA}$ and $4 \mathrm{mg} \mathrm{L}^{-1} \mathrm{NAA}$, along with 30 $\mathrm{g} \mathrm{L}^{-1}$ sucrose. The media that achieved the highest biomass selected after several trials. The MS with PGRs we choose for best callus yield and form. Then Elicitor (GA) and precursor phenylalanine were used in different concentrations. The $\mathrm{pH}$ of the medium was adjusted to 5.7-5.8 before being solidified with $3.0 \mathrm{~g} \mathrm{~L}^{-1}$ phytagel, then autoclaved at a pressure of $1.06 \mathrm{~kg} / \mathrm{cm}^{2}$ and $121^{\circ} \mathrm{C}$ for 15 minutes. The cultures were then incubated at approximately $25 \pm 2{ }^{\circ} \mathrm{C}$ with a $16 \mathrm{hr}$. photoperiod under cool white fluorescent tubes. Trying to enhance the production of $\mathrm{CPF}$ and AMF, different concentrations of an elicitor and a precursor were applied. The elicitor chosen was GA3 at concentrations of $1,2,4$, and $8 \mathrm{mg} \mathrm{L}^{-1}$, extracts abbreviated CG1, CG2, CG3, and CG4, respectively. The precursor used was PAL at concentrations of 5,10,20, and 40 $\mathrm{mg} \mathrm{L}^{-1}$, extracts abbreviated $\mathrm{CF} 1, \mathrm{CF} 2, \mathrm{CF} 3$, and $\mathrm{CF} 4$, respectively. A control medium was done on (MS) only without addition of any PGRs to compare results. The composition of all the culture media is presented in Table 1.

Table I Types of treatment (media used and components concentration)

\begin{tabular}{lllll}
\hline & \multicolumn{2}{l}{ Medium and (PGRS) } & \multicolumn{2}{l}{$\begin{array}{l}\text { Elicitors and } \\
\text { precursors }\end{array}$} \\
\hline $\begin{array}{l}\text { Callus } \\
\text { name }\end{array}$ & $\begin{array}{l}\text { MS } \\
\text { medium }\end{array}$ & $\begin{array}{l}\text { BA/NAA } \\
\left(\mathbf{m g ~ L}^{-1}\right)\end{array}$ & $\begin{array}{l}\mathbf{G A}_{3} \\
\left(\mathbf{m g ~ L}^{-1}\right)\end{array}$ & $\begin{array}{l}\text { PAL } \\
\left.\mathbf{L}^{-1}\right)\end{array}$ \\
\hline Control & + (a) $^{(2)}$ & $0.0 / 0.0$ & 0 & 0 \\
$\mathrm{CFI}$ & + & $0.5 / 4$ & 0 & 5 \\
$\mathrm{CF} 2$ & + & $0.5 / 4$ & 0 & 10 \\
$\mathrm{CF} 3$ & + & $0.5 / 4$ & 0 & 20 \\
$\mathrm{CF} 4$ & + & $0.5 / 4$ & 0 & 40 \\
$\mathrm{CG1}$ & + & $0.5 / 4$ & 1 & 0 \\
$\mathrm{CG} 2$ & + & $0.5 / 4$ & 2 & 0 \\
$\mathrm{CG} 3$ & + & $0.5 / 4$ & 4 & 0 \\
$\mathrm{CG} 4$ & + & $0.5 / 4$ & 8 & 0 \\
\hline
\end{tabular}

(a) $=$ Present

\section{Sample preparation for HPLC analysis}

\section{From plants (in vivo) samples}

An equal amount of the leaves of both plant samples under investigation $(\mathrm{CNC}, \mathrm{CFU})$ were separately air-dried and ground into a fine homogeneous powder and one gram of each was exhaustingly 
extracted with $15 \mathrm{~mL}$ HPLC grade methanol three times. The extracts were mixed, evaporated to dryness and weighed to give $110 \mathrm{mg}$ and $100 \mathrm{mg}$ for CNC and CFU samples, respectively. All samples prepared were kept refrigerated in amber glass vials till time of analysis. For quantitative determination of $\mathrm{CPF}$ content, $5 \mathrm{mgml}^{-1}$ of $\mathrm{CNC}$ and $2.5 \mathrm{mgml}^{-1}$ of $\mathrm{CFU}$ and for AMF analysis, $5 \mathrm{mgml}^{-1}$ of $\mathrm{CNC}$, and $100 \mathrm{mgml}^{-1}$ of CFU were prepared in acetonitrile: DMSO $(1: 1, \mathrm{v} / \mathrm{v})$ of which $5 \mu \mathrm{L}$ was injected in triplicates and the peak areas were measured.

\section{From the callus (in vitro) samples}

The callus replicates obtained from leaves of $C$. sempervirens $L$. with different treatments were weighted as fresh weight and then completely dried in an oven at a temperature not exceeding $45{ }^{\circ} \mathrm{C}$ and the dry weights were recorded. Each one of the nine dry callus samples was powdered in a mortar and extracted successively three times with $15 \mathrm{ml}$ HPLC grade methanol. These extracts were dried under vacuum and weights are recorded and expressed as extracts dry weights as shown in Table 2. For quantitative determination of CPF content, $10 \mathrm{mg} / \mathrm{mL}$ of the callus extracts $(\mathrm{CF} 1, \mathrm{CF} 2, \mathrm{CF} 3, \mathrm{CF} 4, \mathrm{CG} 1$, CG2, CG3, and CG4) as well as $10 \mathrm{mgml}^{-1}$ of the callus control, were prepared in a solution mixture of acetonitrile: $\operatorname{DMSO}(1: 1, \mathrm{v} / \mathrm{v})$. For AMF analysis, $100 \mathrm{mgml}^{-1}$ of each of the callus extracts (CF1, CF2, $\mathrm{CF} 3, \mathrm{CF} 4, \mathrm{CG} 1, \mathrm{CG} 2, \mathrm{CG} 3$, and CG4) and $100 \mathrm{mgml}^{-1}$ the callus control extract, were prepared in the same solvent mentioned before. Then $5 \mu \mathrm{L}$ of each of the above solutions was injected in triplicate and the peak areas were measured.

Table 2 Weights of in vitro produced callus in different media

\begin{tabular}{|c|c|c|c|}
\hline $\begin{array}{l}\text { Callus } \\
\text { Name }\end{array}$ & $\begin{array}{l}\text { Fresh Weight of } \\
\text { Callus (g jar') }\end{array}$ & $\begin{array}{l}\text { Dry Weight } \\
\text { of Callus ( } g \\
\left.\text { jar }^{-1}\right)\end{array}$ & $\begin{array}{l}\text { Extract } \\
\text { Weight (mg) }\end{array}$ \\
\hline Control & 5.723 & 0.298 & 160 \\
\hline CFI & 8.151 & 0.359 & 170 \\
\hline CF2 & $3.4 I$ & 0.267 & 180 \\
\hline CF3 & 3.304 & 0.246 & 120 \\
\hline CF4 & $|2.89|$ & 0.509 & 150 \\
\hline CGI & 12.978 & 0.475 & 270 \\
\hline CG2 & 14.329 & $0.48 I$ & 230 \\
\hline CG3 & 9.862 & 0.406 & 260 \\
\hline CG4 & 4.169 & 0.243 & 150 \\
\hline
\end{tabular}

\section{Method validation}

The developed method was validated according to the ICH guidelines ${ }^{21}$ for various parameters such as system suitability, limit of detection (LOD), limit of quantitation (LOQ), linearity, accuracy, precision, and robustness. Selectivity and system suitability method selectivity was evaluated by injecting standard solution mixture containing CPF and AMF $\left(20 \mu \mathrm{gmL}^{-1}\right)$ and sample extract $(5.0 \mathrm{mg}$ of methanol extract in $10 \mathrm{ml}$ of (Acetonitrile: DMSO; 1:1, v/v). The purity of peak of interest was assessed using diode array detector. The system suitability of the proposed chromatographic conditions was studied in terms of resolution, tailing factor and repeatability of peak area.

\section{Linearity}

For linearity studies, different aliquots of CPF and AMF stock standard solution were taken in $5.0 \mathrm{ml}$ volumetric flasks and diluted up to mark with acetonitrile to obtain final concentrations of $(0.5,1$, $\left.2,5,10,20,25,30,40 \mu \mathrm{gml}^{-1}\right)$ for both CPF and AMF, respectively. From the resulting solutions $(5 \mu \mathrm{L})$ were injected in triplicate in HPLC system and average area was calculated. Graph of average area and concentration was plotted and correlation coefficient $\left(\mathrm{r}^{2}\right)$ was calculated (Figure 4). The linearity equation was calculated by linear regression analysis. Limit of detection and limit of quantitation

$\mathrm{LOD}$ and $\mathrm{LOQ}$ were determined as $\mathrm{LOD}=3.3 \sigma / \mathrm{S}$ and $\mathrm{LOQ}=10 \sigma / \mathrm{S}$. Where $\sigma=$ standard deviation of the response and $\mathrm{S}=$ the slope of the corresponding calibration curve.

\section{Accuracy}

Accuracy of the method was determined by calculating recovery of sample. Accuracy was measured at three different levels $(0.5,5$ and $20 \mu \mathrm{gmL}^{-1}$ ) of test concentrations and $\%$ recovery was calculated. Accuracy is expressed as the percent relative error (\% RE) which was calculated by the following equation: $\% \mathrm{RE}=[$ (calculated concentration-theoretical concentration)/theoretical concentration] $\times$ 100 . The $\%$ RSD was within $\pm 15 \%$ as required by the ICH guidelines. ${ }^{21}$

\section{Precision}

Repeatability (intraday) and intermediate precision (interday) were determined by triplicate injections of samples at three levels that were $\left(0.5,5,20 \mu \mathrm{gmL}^{-1}\right)$ of test concentrations of both CPF and AMF each repeated three times on three successive days. Peak area corresponding to $\mathrm{CPF}$ and $\mathrm{AMF}$ was noted at each level, concentration was determined and intraday and interday precision was expressed as $\%$ relative standard deviation ( $\%$ RSD). The relative standard deviation was calculated as follows:\% $\mathrm{RSD}=$ (standard deviation/ mean $) \times 100$. Acceptance criteria for precision were as follows: the $\%$ RSD was lower than $15 \%$, for both inter- and intraday precision, according to ICH guidelines. ${ }^{21}$

\section{Robustness}

Robustness of the developed method was evaluated by deliberately changing method parameters such as mobile phase flow rate $(0.9,1.0$ and $\left.1.1 \mathrm{ml} \mathrm{min}^{-1}\right)$, column oven temperature $\left(24,25\right.$ and $\left.26^{\circ} \mathrm{C}\right)$ and detection wavelength $(330,331$ and $329 \mathrm{~nm})$, and their effect on peak area and retention time was observed. Which resulted in a very slight change in the retention time and tailing factor was observed. This indicates the robustness of the proposed method. 


\section{Results and discussion}

The use of mobile phase consisted of water and acetonitrile (60:40:0.1\%FA) gave the optimum results to separate CPF and AMF. Peak area of each flavonoid was detected at $330 \mathrm{~nm}$ (Figure 2) and the column oven temperature was maintained at $25^{\circ} \mathrm{C}$. The HPLC-DAD method is considered to be specific as the complete separation of CPF and $\mathrm{AMF}$ was observed. The average retention time \pm S.D. for $\mathrm{CPF}$ and AMF were found to be $5.061 \pm 0.0004 \mathrm{~min}$. and $6.865 \pm 0.0005 \mathrm{~min}$., respectively, for nine replicates (Figure 3A). The method was found to be suitable for the analysis and application on tissue cultured samples as the resolution (Rs) was $\geq 2.62$, selectivity was $1.47-3.15$, and tailing factor $\leq 1.12$. The system suitability test results of the proposed method are presented in (Table 3). The method was found to be linear over the concentration range $0.5-40 \mu \mathrm{gmL}^{-1}$ with correlation coefficient $\left(\mathrm{r}^{2}\right) \geq 0.999$ demonstrating an acceptable data fit to the regression line. The limit of detection (LOD) and the limit of quantification (LOQ) were calculated according to the current ICH guidelines as the ratio of 3.3 and 10 standard deviations of the response $(n=9)$, respectively, and the slope of the calibration curve. ${ }^{21}$ LOD was recorded as 0.15

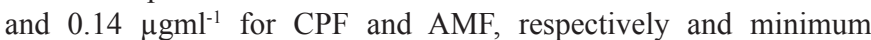
concentration at which analyze can be reliably quantified; LOQs were found to be 0.47 and $0.43 \mu \mathrm{gml}^{-1}$ for CPF and AMF, respectively (Table 4). The intraday precision and accuracy of the method was assessed by determination of three concentration level of CPF and AMF each repeated six times within a day and the interday precision and accuracy of the method was determined using three concentration level of CPF and AMF each repeated three times on three different days. Precision of the method was expressed as relative standard deviation (RSD\%), the obtained results are within the accepted criteria and the precision range is $0.66 \%-3 \%$, which indicates that the proposed method is precise, according to ICH guidelines. ${ }^{21}$ While accuracy was expressed as relative error (RE\%), the obtained results are within accepted criteria less than $\pm 15 \%$ and ranged from -3.11 to 11.68 which is consistent with ICH guidelines. ${ }^{21}$ The results are shown in Table 5. The developed and validated method was successfully applied for quantitative determination of CPF and AMF. The study revealed that the $\mathrm{CNC}$ leaves contained a higher concentration of the active components than $\mathrm{CFU}$ where each gram of $\mathrm{CNC}$ contained $0.67,0.46 \mathrm{mg}$ of $\mathrm{CPF}$, and $\mathrm{AMF}$ respectively, whereas the same weight of CFU had $0.35,0.014 \mathrm{mg}$ of CPF and AMF, respectively. Control callus media showed that each gram dry weight contained 1.73 and $0.013 \mathrm{mg}$ of CPF and AMF, respectively. Which indicates that the MS media only (control medium) without any additives, elicitors or precursors, could produce higher amounts of CPF than native plants (CNC and $\mathrm{CFU})$ ? It is also clear from the results that the native plants: $\mathrm{CNC}$ and $\mathrm{CFU}$ contained higher amounts of AMF than the callus tissue cultured media, however, AMF is also produced in callus media (Table 6). Reviewing the available literature indicates that this the first attempt to analyze these biflavonoids (CPF, AMF) from tissue culture media in addition to native plants. The novelty of our method have come from the combination between tissue culture micro propagation technique and chromatographic separation techniques, attempting to determine the optimum conditions for the production of bioactive compounds (biflavonoids) by determination of the produced content. Acceptable system suitability parameters were calculated for the proposed chromatographic method which ensures that the method is adequate for the quantitative analysis of that binary mixture (Table 1). The proposed method was validated according to ICH guidelines
(Table 2). In addition, this chromatographic method can successfully be applied for the simultaneous determination of both components in their tissue cultured extract or native plant extracts (Table 3 ). The most important feature of method development in liquid chromatography is to achieve sufficient resolution of the two studied compounds at a reasonable analysis time. To optimize the HPLC assay parameters, the mobile phase composition was studied. Several mobile phases were tried in order to achieve the best chromatographic separation. Reasonable resolution between the two compounds could not be obtained using mobile phase containing a mixture of methanol with water. Also, acetonitrile or methanol with various buffers was tried, but, the peaks of the two compounds were not resolved from each other. A mobile phase consisting of a mixture of water: acetonitrile: formic acid (60:40: $0.1 \%, \mathrm{v} / \mathrm{v})$ provided the best separation of the studied compounds with a satisfactory resolution. From the literature it is well known that most flavonoids are characterized by the presence of two major absorption bands in the ultraviolet/visible region, Band I in the $320-385 \mathrm{~nm}$ range and Band II in the $250-285 \mathrm{~nm} \cdot 2^{2-24}$ The data are consistent with the recorded observations from ultraviolet spectrum of Cupressuflavone and amentoflavone (Figure 2). Hence, the selection of the wavelength maximum at $330 \mathrm{~nm}$ was satisfactory for determination of both CPF and AMF. The specificity of the HPLCDAD method is determined where baseline separation was obtained between $\mathrm{CPF}$ and $\mathrm{AMF}$ with no interference from other components of the callus extract or the $C$. sempervirens plants extract. The representative chromatograms obtained from samples are presented in Figures 3B-3D. Complete separation of CPF and AMF was observed at the selected wavelength (Figure 3 ). The average retention time \pm S.D. for CPF and AMF were found to be $5.061 \pm 0.0004 \mathrm{~min}$. and $6.865 \pm 0.0005 \mathrm{~min}$., respectively, for nine replicates. The system suitability parameters such as retention time, retention factor, tailing factor, the number of theoretical plates for $\mathrm{CPF}$ and $\mathrm{AMF}$ peaks were calculated. All parameters tested met the acceptance criteria on all days. The system suitability test parameters ensure the validity of the method as well as confirm the resolution between different peaks of interest. The system suitability test results of the proposed method are presented in Table 3.
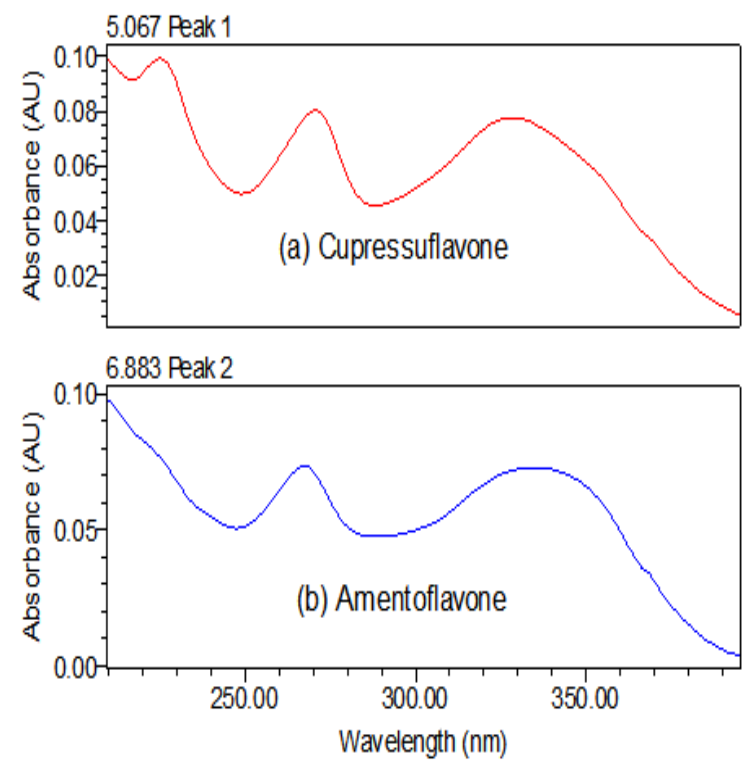

Figure 2 Ultraviolet spectrum of A, Cupressuflavone; B,Amentoflavone. 


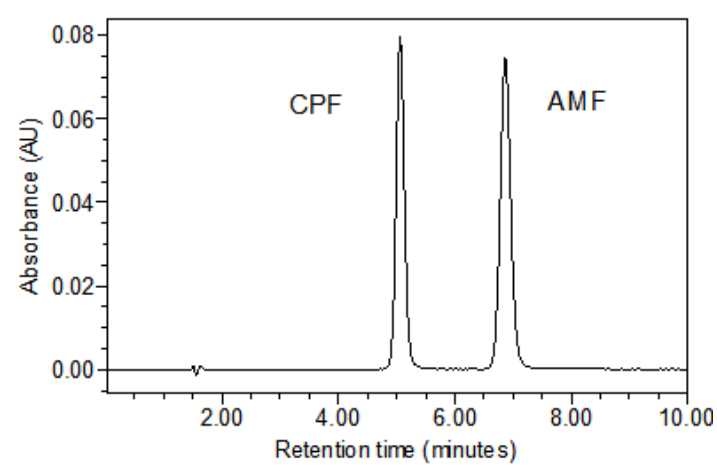

A

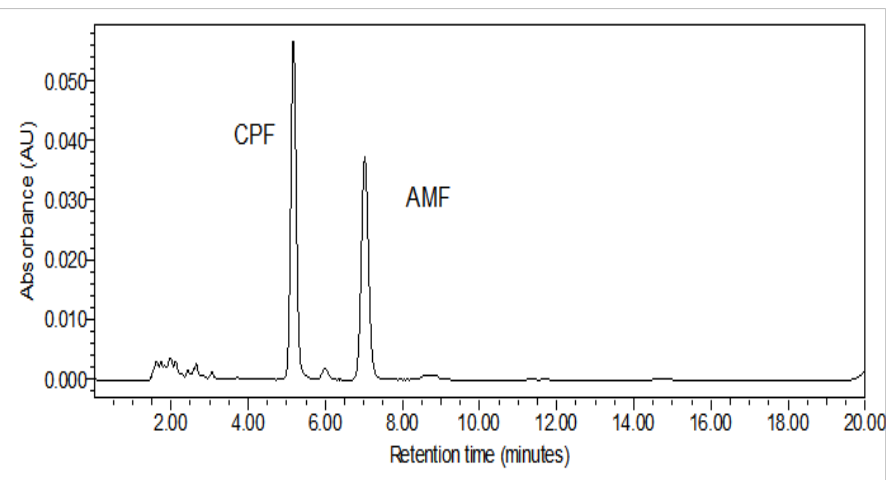

B

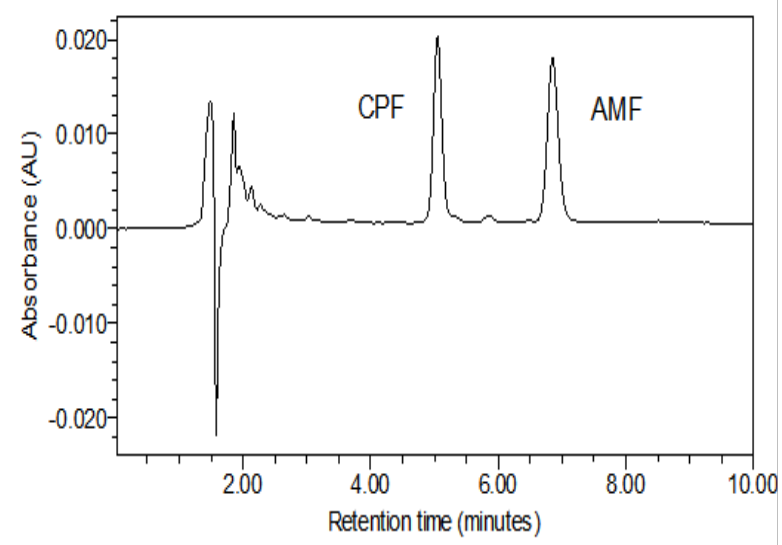

C

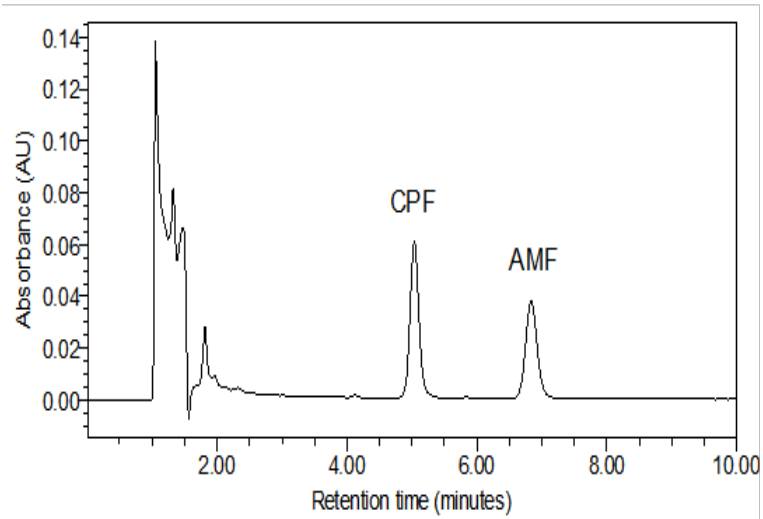

D

Figure $3 \mathrm{HPLC}$ chromatograms of $5 \mu \mathrm{L}$ injection volume of A, binary prepared mixture of $40 \mu \mathrm{mL}^{-1}$ of standards $\mathrm{CPF}$ and AMF; $B, 5 \mathrm{mg} \mathrm{mL}^{-1}$ of $\mathrm{CNC} ; \mathrm{C}, 2.5 \mathrm{mg}$ $\mathrm{mL}^{-1} \mathrm{CFU} ; \mathrm{D}, 100 \mathrm{mg} \mathrm{mL}^{-1}$ control under the specified experimental conditions.

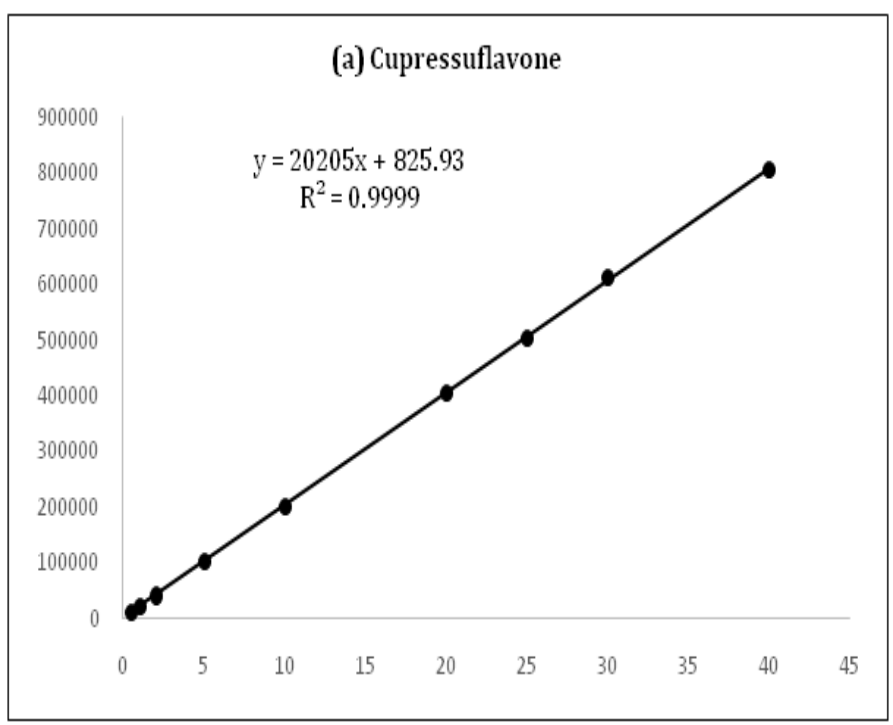

A

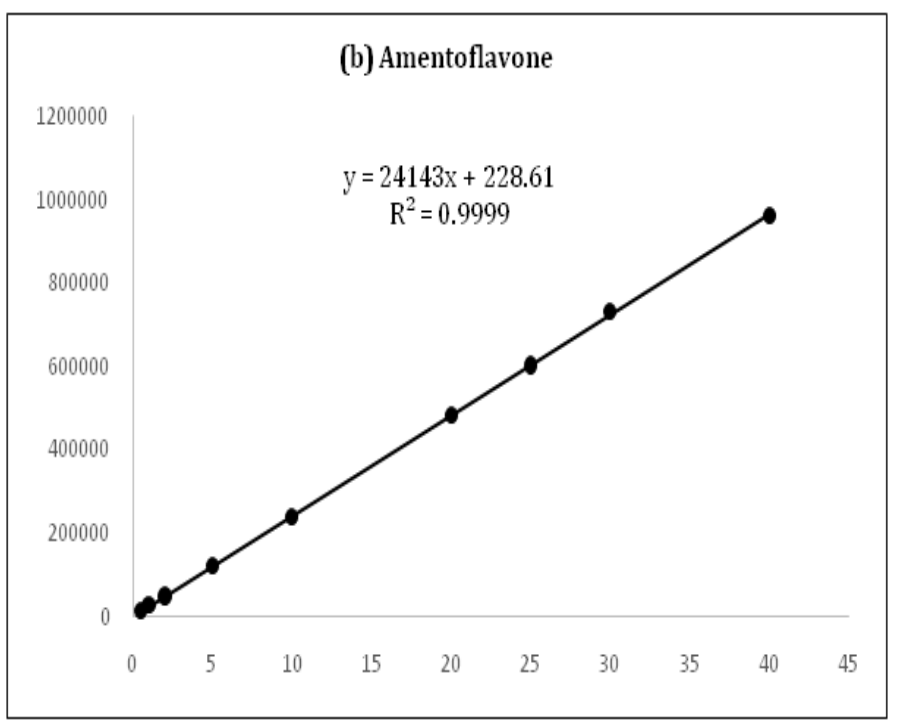

Figure 4 Calibration curves and regression equations of $\mathrm{A}$, Cupressuflavone; B, Amentoflavone.

Table 3 System suitability test results of the developed method for determination of CPF and AMF

\begin{tabular}{|c|c|c|c|c|c|}
\hline Compound & $\begin{array}{l}\text { Retention } \\
\text { Time } \\
\text { (min) } \\
\text { Mean士S.D. } \\
\text { a }\end{array}$ & $\begin{array}{l}\text { Retention } \\
\text { Factor } \\
\text { (K/) }\end{array}$ & $\begin{array}{l}\text { Resolution } \\
\text { Rs }\end{array}$ & $\begin{array}{l}\text { Selectivity } \\
\alpha\end{array}$ & $\begin{array}{l}\text { Tailing } \\
\text { Factor }\end{array}$ \\
\hline CPF & $\begin{array}{l}5.061 \pm \\
0.0004\end{array}$ & 2.51 & $2.62\left(a_{1}\right)$ & $3.15\left(b_{1}\right)$ & 1.12 \\
\hline AMF & $\begin{array}{l}6.865 \pm \\
0.0005\end{array}$ & 3.76 & $3.45\left(a_{2}\right)$ & $1.47\left(b_{2}\right)$ & 1.11 \\
\hline
\end{tabular}

a Mean of retention time in minutes \pm S.D. for 9 determinations. a, $b$ are $\alpha$ and Rs calculated for CPF and AMF, respectively. 
Table 4 Characteristic parameters of the regression equation of the proposed HPLC method for determination of CPF and AMF

\begin{tabular}{lll}
\hline Parameters & CPF & AMF \\
\hline Calibration range $\left(\mu g \mathrm{~mL}^{-1}\right)$ & $0.5-40$ & $0.5-40$ \\
Regression equation $\left(\mathrm{Y}^{\mathrm{a}}\right.$ & & $24.143 \times 10^{3}$ \\
Slope $(\mathrm{b})$ & $20.205 \times 10^{3}$ & 268.78 \\
$\left(\mathrm{~S}^{2}\right)$ Standard deviation of the slope $\left(\mathrm{S}^{\mathrm{b}}\right)$ & 228.43 & $1.1 \mathrm{I}$ \\
Relative standard deviation of the slope $\left(\mathrm{S}^{\mathrm{b}}\right)$ & 1.13 & $23.931 \times 10^{3}-24.355 \times 10^{3}$ \\
Confidence limit of the slope ${ }^{\mathrm{b}}$ & $20.025 \times 10^{3}-20.385 \times 10^{3}$ & 228.6 \\
Intercept $(\mathrm{a})$ & 825.93 & 5416.78 \\
Standard deviation of the intercept & 4603.54 & $-40.4094 \times 10^{2}-44.9816 \times 10^{2}$ \\
Confidence limit of the slope ${ }^{\mathrm{b}}$ & $-28.026 \times 10^{2}-4.4545 \times 10^{2}$ & 0.9999 \\
Correlation coefficient $\left(\mathrm{r}^{2}\right)$ & 0.9999 & 0.14 \\
Detection limit $\left(\mu g \mathrm{~mL}^{-1}\right)$ & 0.15 & 0.43 \\
Quantitation limit $\left(\mu g \mathrm{~mL}^{-1}\right)$ & 0.47 & \\
\hline
\end{tabular}

${ }^{a} \mathrm{Y}=\mathrm{a}+\mathrm{bc}$, where $\mathrm{c}$ is the concentration of the substance in $\mu \mathrm{g} \mathrm{mL}^{-1} ; \mathrm{Y}$ is the peak area; $\mathrm{a}=$ intercept; $\mathrm{b}=$ the slope of the calibration curve เ95\% confidence limit, $n=9$

Table 5 Intra-and inter-day precision and accuracy of the proposed HPLC method determined by the recovery of CPF and AMF

\begin{tabular}{|c|c|c|c|c|c|c|c|}
\hline \multirow[t]{2}{*}{ Compound } & \multirow{2}{*}{$\begin{array}{l}\text { Concentration } \\
\left(\mu g \mathrm{~mL}^{-1}\right)\end{array}$} & \multicolumn{3}{|c|}{ Intraday Precision and Accuracy } & \multicolumn{3}{|c|}{ Interday Precision and Accuracy } \\
\hline & & (Mean $\pm S . D.)^{a}$ & RSD\% & RE\% & (Mean $\pm S . D.)^{a}$ & RSD\% & RE\% \\
\hline \multirow{3}{*}{ CPF } & 0.5 & $0.52 \pm 0.01$ & 2.64 & 4.31 & $0.52 \pm 0.01$ & 2.1 & 3.36 \\
\hline & 5 & $4.96 \pm 0.07$ & 1.45 & -0.73 & $4.90 \pm 0.07$ & 1.3 & -2.08 \\
\hline & 20 & $19.90 \pm 0.20$ & 1 & -0.67 & $19.70 \pm 0.16$ & 0.8 & -1.59 \\
\hline \multirow{3}{*}{ AMF } & 0.5 & $0.56 \pm 0.02$ & 3 & 11.68 & $0.55 \pm 0.01$ & 2.3 & 9.54 \\
\hline & 5 & $5.01 \pm 0.03$ & 0.66 & 0.19 & $4.80 \pm 0.14$ & 3 & -3.11 \\
\hline & 20 & $9.80 \pm 0.10$ & 0.7 & -0.89 & $19.70 \pm 0.13$ & 0.7 & $-1.4 \mid$ \\
\hline
\end{tabular}

a Mean and Standard deviation for six determinations per day

Table 6 Determination of CPF and AMF in plants (In Vivo) and in callus (In Vitro) samples using the proposed HPLC-DAD method

\begin{tabular}{|c|c|c|}
\hline \multirow[b]{2}{*}{ Examined sample } & \multicolumn{2}{|c|}{$\mu \mathrm{g}^{-1}$ Dry weight (Mean \pm S.D.) a } \\
\hline & Cupressuflavone & Amentoflavone \\
\hline CNC & $670 \pm 0.027$ & $462 \pm 0.011$ \\
\hline CFU & $357 \pm 0.006$ & $|5 \pm 0.00|$ \\
\hline Callus Control & $1730 \pm 0.009$ & $|3 \pm 0.00|$ \\
\hline CFI & $380 \pm 0.005$ & $5 \pm 0.001$ \\
\hline CF2 & $160 \pm 0.007$ & (b) \\
\hline CF3 & $520 \pm 0.006$ & $4 \pm 0.001$ \\
\hline CF4 & $350 \pm 0.001$ & $5 \pm 0.002$ \\
\hline CGI & $1480 \pm 0.0096$ & $|I \pm 0.00|$ \\
\hline CG2 & $700 \pm 0.008$ & $9 \pm 0.003$ \\
\hline CG3 & $1320 \pm 0.018$ & $13 \pm 0.002$ \\
\hline CG4 & $430 \pm 0.003$ & $9 \pm 0.001$ \\
\hline
\end{tabular}

a Mean concentration found in $\mathrm{mg}$ per gm samples \pm standard deviation for three determinations.

bBelow limit of detection

Citation: Ibrahim EA, Desoukey SY, Hadad GM, et al. Analysis of cupressuflavone and amentoflavone from Cupressus sempervirens L. and its tissue cultured callus using HPLC-dad method. Pharm Pharmacol Int J. 20I7;5(5): I74-I80. DOI: I0.15406/ppij.20I7.05.00I34 


\section{Conclusion}

The developed method for qualitative and quantitative determination of Cupressuflavone and amentoflavone was validated and was successful in the determination of the analyses of interest without any matrix interference. All validation parameters were achieved and were satisfactory. The procedure was relatively simple, precise, accurate and fast as the extracts are evaluated without previous steps of purification. This study also clarified the success of callus micro propagation of $C$. sempervirens $L$. leaves in the production of these bioactive compounds, especially $\mathrm{CPF}$ which could be promising in the future.

\section{Acknowledgements}

The authors wish to thank Dr. Mohamed Reda Abd Almegid Abd Alhady, Dr. Reda El-Said Abo El-Fadl, and Dr. Ghada Abd ElMoneim Hegazi, for their help in preparing tissue culture samples. Tissue Culture Unit, Genetic Resources Department, Ecology and Dry Land Agriculture Division, Desert Research Center, 11753 ElMatareya, Mathaf El-Matareya St., Cairo, Egypt. This work is fully funded by the Egyptian embassy (Egyptian and Cultural Bureau), Washington DC, USA.

\section{Conflict of interest}

Author declares that there is no conflict of interest.

\section{References}

1. Rawat P, Khan MF, Kumar M, Tamarkar AK, Srivastava AK, et al. (2010) Constituents from fruits of Cupressus sempervirens. Fitoterapia. 2010;81(3):162-166

2. Guarrera P. The Ethnobotanical Heritage of Lazio. Plant Biosystem. $1994 ; 128(1): 446$

3. Harborne JB, Mabry TJ. The flavonoids: advances in research. Switzerland: Springer US; 1982. p. 1-744.

4. Tulin A. The significance of flavonoids as a potential anti-tuberculosis compounds. Research \& Reviews: Journal of Pharmacology and Toxicological Studies. 2015;3:1-17

5.Hegnauer R. Oenotheraceae. Chemotaxonomy of Plants: Textbooks and monographs from the field of exact sciences. Springer; $1969 ; 14-35: 22-226$.

6. Gadek P, Quinn C. Biflavones of the subfamily Cupressoideae, Cupressaceae. Phytochemistry. 1985;24(2):267-272.

7. Romani A, Galardi C, Pinelli P, et al. HPLC quantification of flavonoids and biflavonoids in Cupressaceae leaves. Chromatographia. 2002;56(7-8):469-474.

8. Iwu MM, Igboko OA, Okunji CO, et al. Antidiabetic and aldose reductase activities of biflavanones of Garcinia kola. J Pharm Pharmacol. 1990;42(4):290-292.
9. Lin YM, Anderson H, Flavin MT, et al. In vitro anti-HIV activity of biflavonoids isolated from Rhus succedanea and Garcinia multiflora. $J$ Nat Prod. 1997;60(9):884-888.

10. Vlietinck A, De Bruyne T, Apers S, et al. Plant-derived leading compounds for chemotherapy of human immunodeficiency virus (HIV) infection. Planta Med. 1998;64(2):97-109.

11. Bagla VP, McGaw LJ, Elgorashi EE, et al. Antimicrobial activity, toxicity, and selectivity index of two biflavonoids and a flavone isolated from Podocarpus henkelii (Podocarpaceae) leaves. BMC complement Altern Med. 2014;14:383.

12. Lin YM, Flavin MT, Schure R, et al. Antiviral activities of biflavonoids Planta Med. 1999;65:120-125.

13. Zembower DE, Lin YM, Flavin MT, et al. Robustaflavone, a potential non-nucleoside anti-hepatitis B agent. Antiviral Res. 1998;39(2):81-88.

14. Iwu MM, Igboko OA, Elekwa OK, et al. Prevention of thioacetamideinduced hepatotoxicity by biflavanones of Garcinia kola. Phytotherapy Res. 1990;4(4):157-159.

15. Anand K, Gupta V, Rangari V, et al. Structure and hepatoprotective activity of a biflavonoid from Canarium manii. Planta Med. 1992;58(6):493-495.

16. Al-Sayed E, Abdel-Daim MM. Protective role of Cupressuflavone from Cupressus macrocarpa against carbon tetrachloride-induced hepato-and nephrotoxicity in mice. Planta Med. 2014;80(18):1665-1671.

17. Ogunwa TH. Molecular interaction of Natural biflavonoids as competitive agonists with aromatase related breast cancer: an in silico approach. Mintage Journal of Pharmaceutical and Medical Sciences. 2016;5(Suppl 4):7-15.

18. Heimler D, Pieroni A. High-performance quantitative thin-layer chromatography of flavonoid glycosides and biflavonoids of Cupressus sempervirens in relation to cypress canker. Chromatographia. 1991;31(5-6):247-250.

19. Baldi A, Romani A, Mulinacci N, et al. The relative antioxidant potencies of some polyphenols in grapes and wines. ACS Symposium series. 1997;661(13):166-179.

20. Murashige T, Skoog F. A revised medium for rapid growth and bioassays with tobacco tissue cultures. Physiologia Plantarum. 1962;15(3):473-497.

21. ICH Harmonised Tripartite Guideline. Q2 (R1) Validation of analytical procedures: Text and Methodology. Geneva; 2005:1-17.

22. Mabry TJ, Markham K, Thomas M. The ultraviolet spectra of flavones and flavonols. The systematic identification of flavonoids. Berlin; 1970. p. 41-164.

23. Markham KR. Flavones, flavonols and their glycosides. Methods in plant biochemistry. 1989;1:197-235.

24. Rice-Evans CA, Miller NJ, Paganga G. Structure-antioxidant activity relationships of flavonoids and phenolic acids. Free Radic Biol Med. 1996;20(7):933-956. 